\title{
Pensar a educação em tempos pós-metafísicos: a alternativa do Interacionismo simbólico ${ }^{1}$
}

\author{
Cláudio Almir Dalbosco* \\ Universidade de Passo Fundo \\ Renata Maraschin** \\ Universidade de Passo Fundo
}

Resumo $\mathrm{O}$ artigo reflete sobre a importância do Interacionismo simbólico fundado por Georg Herbert Mead (1863-1931) para pensar a educação em contexto social plural e complexo, marcado por formas pós-metafísicas de pensamento. Estrutura-se em duas partes. Na primeira reconstroem-se os conceitos de educação como "extrair de dentro uma essência dada a priori (concepção tradicional metafísica) e como interação mediada simbolicamente (concepção pós-metafísica). Na segunda, investiga-se o núcleo conceitual do Interacionismo simbólico, importante para pensar a educação no contexto contemporâneo. Justifica a importância da ação humana compreendida como interação mediada simbolicamente para pensar a educação como um processo de reconhecimento recíproco, para fazer frente ao individualismo contemporâneo, representado pela fragmentação do Self. Por fim, procura extrair da reflexão sobre a constituição linguística do Self algumas referências éticas à educação contemporânea.

PALAVRAS-CHAVE: Georg Herbert Mead; Interacionismo simbólico; Self; Ação simbólica; Educação. 


\section{Thinking the education at post-metaphysical times: the alternative of symbolic interactionism}

Abstract The article reflects on the importance of symbolic interactionism founded by Georg Herbert Mead (1863-1931) to think education in plural and complex social context, marked by post-metaphysical ways of thinking. It is divided into two parts. In the first the concepts of education as "extracting from within an essence given a priori" (traditional metaphysics conception) and as symbolically mediated interaction (post-metaphysical conception) are reconstructed. In the second, the conceptual core of the symbolic interactionism that is important to think about education in the contemporary context is investigated. Justifies the importance of the human action understood as symbolically mediated interaction to think the education as a mutual recognition process, to confront the contemporary individualism represented by Self fragmentation. Finally, it seeks to extract from the reflection on the linguistic constitution of the Self some ethical references to contemporary education.

KEYWORDS: Georg Herbert Mead; Symbolic interactionism; Self; Symbolic action; Education.

\section{Introdução}

O artigo reflete sobre a importância do Interacionismo simbólico, elaborado em sua versão original pelo filósofo americano Georg Herbert Mead (1863-1931), para pensar a educação no contexto social plural e complexo, marcado por formas pós-metafísicas de pensamento. Nas sociedades plurais, diferentemente das sociedades tradicionais, a autoridade encontra-se descentrada, fragmentada, não sendo mais legitimada pela força do grupo canalizada pelas instituições tradicionais, como família, escola e igreja. O pluralismo e descentração de formas de vida contemporânea exigem outros modos de constituição do Self, não mais centrado no modelo da consciência substancial.

O tratamento dado ao tema deixa-se justificar com base em dois argumentos. No primeiro está o Interacionismo simbólico como corrente de pensamento pósmetafísica que por sua pertença ao pragmatismo enseja uma caracterização mundana (materialista) do pensar e do refletir filosófico. Neste contexto, o Interacionismo simbólico acredita que os problemas do mundo que está aí, enquanto mundo da experiência social e humana, somente podem ser resolvidos sob a tutela do saber científico, mediante um direcionamento prático das ações. Portanto, enquanto postura filosófica pós-metafísica, o Interacionismo simbólico se caracteriza por adotar certo materialismo linguístico, compreendendo a ação humana como interação mediada linguisticamente, ao mesmo tempo em que deposita poder transformador à ciência. 
Essa perspectiva mundana do pensar pode ser conectada a uma compreensão de Educação não mais como "extrair de dentro uma essência dada a priori” (concepção tradicional metafísica)2, mas como interação na qual os sujeitos se constituem. Ou seja, a constituição do Self (si mesmo) ocorre simbolicamente na relação com os outros e na vivência em uma comunidade concreta. Trata-se aqui nitidamente do abandono da noção da consciência (mente) como substância (metafísica da subjetividade) à noção do Self constituído pela linguagem, por meio da interação mediada simbolicamente. Precisamente neste contexto é que Georg Herbert Mead tornar-se um autor chave à noção contemporânea de intersubjetividade, pensada em termos pós-metafísicos.

Como segundo argumento para justificar a escolha do tema está o pressuposto de que a escola, enquanto instituição social, não sai incólume às velozes transformações de ordens diversas (econômica, cultural, política) pelas quais passa a sociedade contemporaneamente e que interferem no modo como acontecem os processos educativos. No sentido de compreender os possíveis fundamentos 3 dessas transformações bem como suas interferências sobre os fundamentos educacionais, a delimitação do presente artigo refere-se às concepções que estão na origem dos processos de individualização e de socialização na sociedade plural e complexa. Sendo a escola uma instituição social, torna-se relevante compreender os fundamentos desses processos de individualização e de socialização e como estes podem interferir no desenvolvimento da educação, pois ao compreender os pressupostos daqueles processos e suas decorrências para a educação, talvez seja possível criar condições para repensar o papel da escola também enquanto instância de construção da identidade dos indivíduos, mas não mais no sentido de uma consciência substancial, mas sim nos termos do Self constituído linguisticamente.

$\mathrm{Na}$ tentativa de alcançar o que se propõe, o artigo foi estruturado em duas partes. Na primeira, foram reconstruídos os conceitos de educação como "extrair de dentro uma essência dada a priori” (concepção tradicional metafísica) e de educação como interação mediada linguisticamente. Enquanto na primeira concepção o sujeito educativo é constituído segundo o modelo de uma consciência substancial, cuja potencialidade do saber reside em sua interioridade, na segunda ele é constituído pela interação simbólica que estabelece com outros sujeitos.

$\mathrm{Na}$ segunda parte do artigo, investiga-se o alcance do Interacionismo simbólico de Georg Herbert Mead como fundamento pós-metafísico da educação em sociedades contemporâneas, plurais e complexas, dominadas por formas pós-metafísicas de pensamento. Evidencia-se como o surgimento do Self numa perspectiva social e o conceito de ação humana, definido como interação mediada simbolicamente, são importantes à concepção educacional pós-metafísica. O conceito de ação humana ancorado no Self social construído simbolicamente possibilita pensar a base ética da educação nos termos de um reconhecimento recíproco. 


\section{Educação e sociedade: aspectos metafísicos e pós- metafísicos}

Justificar o nexo estreito entre educação e sociedade é uma tarefa central tanto da filosofia da educação com inspiração na filosofia social, como da sociologia da educação ancorada nas teorias sociológicas clássicas. $\mathrm{Na}$ origem moderna de qualquer uma delas esta o pensamento filosófico e pedagógico desenvolvido por Jean-Jacques Rousseau, sobretudo, em sua obra principal, o Emílio. Como fundador da moderna teoria social, Rousseau pensa a educação como um processo eminentemente social. Para ele, a educação ocorre em sociedade e não há educação fora da história e da sociedade. Rousseau lança as bases para pensar a relação entre sociedade, educação e escola, embora esta última não fora fonte específica de suas preocupações.

Deste modo, seguindo a tradição moderna, inaugurada por Rousseau, a educação e a escola estão inseridas em um contexto social. Considerando isso, não podemos então pensar sociedade, educação e escola como esferas desconectadas, como se as transformações observadas em uma esfera não interferissem na outra. É preciso salientar ainda que as transformações destes conceitos de sociedade, educação e escola não ocorreram ou estão ocorrendo de forma linear, mas dinâmica. Traços do que caracterizou as concepções de sociedade e educação nos diferentes momentos históricos e do que as caracteriza contemporaneamente sobrepõem-se, desafiando os educadores a repensarem, constantemente, o sentido e o propósito da educação na sociedade contemporânea. Ora, é justamente a partir desse dinamismo que surge a possibilidade de serem pensados outros fundamentos para a educação, como o Interacionismo simbólico. Ou seja, o Interacionismo simbólico, como postura intelectual (filosófica, sociológica e pedagógica), é uma maneira atualizada, pós-metafísica, de pensar a pluralidade da educação e sua relação complexa, dinâmica, com a sociedade contemporânea.

Dos traços que caracterizaram as concepções de educação e sociedade nos diferentes momentos históricos4, o enfoque será identificar, ainda que de forma breve, as implicações do pressuposto metafísico-teológico e do pressuposto pós-metafísico nas concepções de sociedade e de educação. Isso porque pensar a educação é pensar quem é hoje o ser humano e em que tipo de sociedade ele vive, considerando também o tipo de ser humano e de sociedade que almeja e que papel a escola e a educação desempenham no processo formativo das novas gerações, visando prepará-las para viver em um contexto urbano cada vez mais globalizado e tecnológico.

A busca permanente de transcendência, homogeneidade, universalidade e domínio, que caracterizou o pensamento filosófico e religioso (pensamento metafísico-teológico), na cultural ocidental centrou-se inicialmente em Deus e posteriormente na razão como elementos que nos orientariam e garantiriam a salvação e a segurança de uma vida feliz. Segundo Goergen (2014) essa forma de pensamento se manifestou em diferentes épocas. "Na época dos poetas, impõe-se o modelo de virtude das divindades mitológicas; no tempo dos filósofos, o das essências metafísicas, no período dos teólogos, o da divindade cristã e, finalmente, nos séculos do iluminismo, o modelo da racionalidade científica moderna." (GOERGEN, 2014, p. 24). 
Deste pressuposto metafísico-teológico originou-se o conceito de Educação enquanto fazer desabrochar as potencialidades que repousam na interioridade da alma do educando e que está na base da definição latina de educação. Deste modo, educere significa nada mais nada menos do que extrair de dentro, fazer brotar de dentro a essência pronta que o educando traz consigo ao nascer. Pressupõe-se aqui, nesta forma de pensamento, um inatismo que assegura a existência de estruturas cognitivas prévias ao nascimento. Uma vez que há tais estruturas, então é necessário, do ponto de vista pedagógico, alguém para fazer desabrochar essa essência no educando. Justifica-se, deste modo, a figura do mestre como autoridade inquestionável, pois é o único capaz de fazer desabrochar o conhecimento que reside na interioridade do educando. O modelo clássico é a noção de educação como recordação (anamnese) esboçada por Platão no Menão.

Portanto, desta concepção de educação surge a ideia de autoridade do mestre, ou seja, da autoridade adulta sobre a criança, que caracterizou também a ideia metafísico-teológica de sociedade fechada, tradicional, rigidamente hierarquizada e dominada pelos pressupostos religiosos. Por encontrar na religião o elemento agregador e possuir um caráter mais rural/agrário, na sociedade fechada/tradicional a identidade do sujeito é marcada pela ideia da pertença a um grupo (família, igreja, escola). A identidade e o papel do indivíduo na sociedade eram determinados de antemão pelo grupo. Nesse modelo de sociedade, a autoridade encontrava-se bem localizada na figura do adulto mais velho (pai, padre, professor e prefeito) como o único capaz de extrair de dentro da criança a sua identidade já dada a priori, ou seja, dada de antemão pelo grupo de pertença do indivíduo. Obediência autoritária, submissão irrestrita e a ausência de diálogo marcam, dessa forma, a concepção metafísica/tradicional de Educação.

Pensadores como Jean-Jacques Rousseau (no século XVIII), John Dewey e Piaget (no século XX) e Paulo Freire fazem duras críticas a essa concepção educativa denunciando seu caráter autoritário, vertical e antidialógico, concepção que estaria, portanto, na contramão dos pressupostos e ideais da sociedade moderna. Cada um a sua maneira compreendeu a educação como um processo social, voltando-se contra o conceito internalista de educação, como algo que brota da interioridade do educando. Para estes autores, portanto, a educação ocorre em sociedade e depende sempre da presença de duas ou mais pessoas. São autores herdeiros e fundadores da sociedade moderna. Nesta tradição de pensamento também se insere Georg Herbert Mead, com a singularidade de pensar, como ainda veremos abaixo, a constituição linguística do Self.

No modelo de sociedade moderna, consolidado a partir do século XVIII, em 1789, com a Revolução Francesa, a reivindicação da dignidade humana ganha novos contornos, assumindo pretensões de universalidade antes nunca visto. Com o Iluminismo5 nasce o princípio da igual dignidade entre os homens e iniciam-se os processos de individualização: o indivíduo passa a se conceber com identidade individual, a qual previamente tinha um caráter coletivo, ou seja, o processo de construção da identidade era dado pela pertença ao grupo. $\mathrm{Na}$ sociedade moderna, modifica-se a configuração das relações entre indivíduo e grupo, uma vez que aquele se torna mais independente deste. O reconhecimento do papel do indivíduo precisa ser construído e configurado pelo próprio sujeito e, nesse sentido, o reconhecimento de si próprio não é 
mais dado pela pertença à família, à escola ou à igreja, mas por aquilo que o indivíduo faz de si próprio. De acordo com Giddens, a modernidade

$$
\begin{aligned}
& \text { rompe o referencial protetor da pequena comunidade e da tradição, } \\
& \text { substituindo-as por organizações muito maiores e impessoais. O in- } \\
& \text { divíduo se sente privado e só num mundo em que lhe falta o apoio } \\
& \text { psicológico e o sentido de segurança oferecidos em ambientes mais } \\
& \text { tradicionais (GIDDENS, 2002, p.38). }
\end{aligned}
$$

A identidade individual moderna que se configura no indivíduo como constituidor de seu próprio Self ampliou, por um lado, a independência do indivíduo em relação ao grupo. Por outro, gerou a sensação de solidão, como apontado por Giddens, em um meio social cada vez mais livre dos referenciais do grupo no sentido tradicional. Como decorrência desse processo moderno de construção de identidade, o que se seguiu foi, em maior escala, o estreitamento do eu ao invés de sua expansão e a consequente formação de indivíduos egocêntricos, que se colocam fora da teia de relações sociais, sendo incapazes de partilhar um horizonte de vida comum.

A autonomização das esferas individuais de vida, que tornam o sujeito moderno cada vez mais independente do recurso externo, transcendente a ele, para justificar sua ação, paga o preço de acentuar cada vez mais uma tendência individualista de vida. O resultado disso, como mostra, entre outros, Sennett, a profunda transformação da relação entre o sujeito e a esfera pública, provocando a tirania da intimidade em nome do esfacelamento da esfera pública (SENNETT, 1998).

Esse processo vem sendo amplamente acentuado pelas características das sociedades contemporâneas complexas e plurais, em que, por um lado, os mecanismos de consumo, a globalização e a tecnologia digital tendem a acentuar modos de ser individualistas e hedonistas. Por outro, permitem maior conexão, comunicação e imbricação entre diferentes culturas, povos, gerando hibridismos culturais, novas formas e estilos de vida, além de maior diferenciação e individuação.

Diante dessa configuração complexa, plural e pós-metafísica de sociedade e de educação, como construir identidade a partir de si próprio, sem os referenciais tradicionais? O que significa educar no contexto dessa configuração social complexa, plural, pós-metafísica que já não mais comporta - embora ainda esteja presente - a ideia de educação como extrair, através da autoridade do adulto, de dentro da criança uma essência pronta, dada de antemão pelo grupo? Goergen (2014) indica alguns caminhos quando afirma que

uma das principais diferenças entre a formação tradicional e a contemporânea é a reestruturação do processo formativo, agora baseado em nova constelação cultural destituída das características de estabilidade e permanência e, portanto, mutante, instável e líquida, segundo a conhecida metáfora de Bauman (2001). Essa mudança redefine profundamente a relação ensino-aprendizagem, substituindo a verticalidade monológica pela horizontalidade dialógica. Diálogo e busca, comunicação e construção tornam-se as novas referências da interpretação/leitura do real e dos processos dinâmicos de construção de identidade. (GOERGEN, 2014, p. 29). 
A reestruturação do processo formativo, de acordo com Goergen, implica compreender a passagem de uma concepção estável e fixa de educação como "extrair de dentro uma essência dada a priori” (concepção tradicional metafísica), em que a identidade do sujeito já estava pronta de antemão e era dada pelo grupo ao qual pertencia (sociedade tradicional), para uma concepção de educação como interação. Ora, nesta nova concepção de educação os sujeitos se constituem ou se autoformam, uma vez que a identidade do sujeito não está pronta ou é dada de antemão, mas antes é construída a partir da convivência com o grupo, que não é estanque, mas híbrido, diverso, plural (sociedade aberta/complexa).

Estas transformações do conceito de educação e de sociedade não ocorreram ou estão ocorrendo de forma linear, mas dinâmica, pois convivem entre si, não sem conflito, formas tradicionais e contemporâneas de vida. E é justamente a partir desse dinamismo e conflito que surge a possibilidade de serem pensados outros referencias à educação. Mas trata-se agora de referências originadas de percepções acerca do processo de construção de identidades individuais no contexto de sociedades abertas e plurais. Precisamente neste contexto social contemporâneo é que Georg Herbert Mead procura formular sua teoria da formação linguística do Self, para dar conta da formação plural e aberta das individualidades. Este autor pretendeu ir além da biologia e da metafísica na compreensão da gênese da subjetividade humana, considerando que não existe sujeito pré-existente à interação constituída pela linguagem. Com isso ele funda uma perspectiva histórica de compreender os processos de socialização e de individualização nas sociedades contemporâneas. Como autor eminentemente moderno, Mead não aceita mais nenhum recurso externo à sociedade e ao próprio sujeito para compreender os processos sociais e individuais.

$\mathrm{Na}$ sequência é investigado o alcance do Interacionismo simbólico de Georg Herbert Mead quando tomado como perspectiva pós-metafísica da educação em sociedades contemporâneas, plurais e complexas. Também reflete-se sobre aspectos éticos que resultam desta forma linguística de pensar o si mesmo à educação.

\section{O Interacionismo simbólico como perspectiva pós-metafísi- ca de pensar a educação}

George Herbert Mead, considerado juntamente com William James, Charles Sanders Peirce e John Dewey como uma das figuras mais expressivas do Pragmatismo clássico americano, escola filosófica estabelecida nos Estados Unidos no final do século XIX. (STANFORD ENCYCLOPEDIA OF PHILOSOPHY, 2012). O Pragmatismo tem seu núcleo no conceito filosófico de ação, entendendo o "ser humano como organismo agente, cuja capacidade de produzir e empregar símbolos significativamente permite-lhe interagir ativamente consigo mesmo, com os outros e com o meio físico-social mais amplo". (DALBOSCO, 2010, p.54).

Compreender o sentido filosófico da ação humana na perspectiva pragmatista não é tarefa fácil, pois entre os próprios pensadores pragmatistas tal conceito sofre atuações e variantes específicas. De qualquer forma, como reconhece o sociólogo alemão Hans Joas, estudioso do pragmatismo americano e, na atualidade, um dos 
grandes especialistas do pensamento de Mead, a teoria pragmática da ação abre "novos campos de fenômenos e, ao mesmo tempo, torna necessário repensar os campos conhecidos" (JOAS, 1999, p. 137). Quando se refere especificamente à contribuição de Mead, afirma o seguinte:

Tomado pelo espírito do pragmatismo, [Mead] investigou o tipo de situação de ação em que uma maior atenção nos objetos do ambiente não basta para garantir o êxito da continuidade da ação. O que tinha em mente eram problemas de ação interpessoal. Em situações sociais, o agente é, ele próprio, uma fonte de estímulo para seu parceiro (ibidem, p. 139).

Hans Joas tem presente aqui a influencia que o Behaviorismo de John Watson exercia na teoria da ação do início do século XX. Buscando ir além do comportamentalismo e da determinação do meio na ação humana, Mead afirma que seu sentido repousa no fato de ser uma produção simbólica e, enquanto tal, resultado da interação social entre os sujeitos da ação. Ou seja, parte da tese que somente na ação simbólica "a imediaticidade qualitativa do mundo e de nós mesmos nos é revelada" (ibidem, p. 137). Neste sentido, e este é o aspecto nuclear da teoria da ação de Mead, não há ação humana com sentido fora do espaço social. Também é este aspecto que,como veremos, denota o caráter propriamente social do fenômeno educativo.

Ao conceber o ser humano como um organismo simbólico, o Pragmatismo tece crítica forte ao dualismo corpo-alma que sustentou a filosofia ocidental e a concepção de educação metafísica e tradicional, cuja prioridade é dada à mente (consciência), enquanto entidade autônoma, substancializada, completa em si mesma, independente do corpo e do meio ambiente. Contrapondo-se a essa perspectiva determinista e essencialista de ser humano, o Pragmatismo afirma que o "ser humano pode tanto influenciar quanto ser influenciado pelo ambiente físico social porque possui a capacidade de produzir e de dar significado a símbolos linguísticos. Portanto, o emprego da linguagem garante-lhe a interação significativa com o meio". (DALBOSCO, 2010, p.58).

Além da centralidade no conceito de ação, o Pragmatismo tem em seu cerne outros pressupostos que estão presentes no Interacionismo simbólico de Georg Herbert Mead:

A obra teórica de Mead segue as linhas mestras do pragmatismo americano, que na sua acepção original possuía um tríplice pilar de estruturação: a doutrina da evolução biológica, a confiança na ciência com seu método experimental e a tradição democrática. Além disso, encontramos como postulados fundamentais a confiança na liberdade criativa, na razão dialógica e na capacidade inventiva e inovadora, bem como um novo modo de conceber a relação entre o conhecimento, a realidade e a ação humana que divergia das concepções clássicas vigentes. (CASAGRANDE, 2014, p. 11).

Influenciado pela doutrina da evolução biológica, pela confiança na ciência com seu método experimental e pela tradição democrática, Mead desenvolveu uma teoria original do desenvolvimento da mente, da consciência e do Self (si mesmo) afirmando que estes são constituídos na convivência social, estruturando-se simbolicamente em uma matriz intersubjetiva. 
Mead, dessa forma, apresenta uma hipótese pós-metafísica da origem do Self, sendo o primeiro autor a conciliar o processo de individuação ao de socialização, pois partindo da oposição entre as teorias individualistas e sociais da pessoa humana, posiciona-se em favor de uma concepção social da emergência do Self, sem desconsiderar a dimensão subjetiva. Mas uma vez, nas palavras de Joas:

Mead estabelece em particular, as condições de interação simbólica
e da autorreflexão. Suas análises são orientadas por uma concepção
normativamente ideal da estrutura da ordem social, baseada prin-
cipalmente no ideal do autogoverno democrático combinado com
idéias peirceanas sobre a comunicação livre e irrestrita dentro da
comunidade científica (JOAS, 1999, p. 140).

Ora, tanto a ideia de autogoverno como a de comunicação livre e irrestrita são decisivas à educação pensada num horizonte pós-metafísico. A primeira ideia está na base de uma visão republicana do político que atribui à educação o papel de formação coletiva da vontade. A segunda, da comunicação livre e irrestrita, referencia-se na noção do pedagógico ancorada no diálogo como fonte de mediação dos conflitos educacionais. Qualquer uma destas duas ideias tem seu apoio no sentido filosófico da ação humana concebida como interação mediada simbolicamente.

Mead afirma o processo de construção da identidade por meio do conceito simbólico-interacionista de ação, destacando o elemento simbólico como constitutivo da ação humana. É pela capacidade simbólica que o homem ultrapassa os condicionamentos, diferenciando a ação humana da ação de outros animais. A ação simbólica diz respeito à capacidade humana de significar (atribuir sentido, colocando-se na situação) por símbolos os acontecimentos.

O símbolo abre a possibilidade de incluir o ponto de vista do outro na identidade do indivíduo. Ao abrir possibilidade, o elemento simbólico permite o surgimento da liberdade, da criação ou invenção da identidade pelo próprio indivíduo. Nesse sentido, Mead desenvolve a teoria do Self (si mesmo) baseado em uma dupla dimensão: a dimensão do "I", que se refere à interioridade do sujeito, e a dimensão do "Me", que diz respeito à esfera social externa ao indivíduo. A partir dessa dupla dimensão, a individualidade somente se torna possível a partir da intersubjetividade. Dessa forma, a construção do Self na perspectiva de Mead é sempre um processo social, conflitivo e tensional entre o I e o Me. Deste modo, embora o I represente mais a perspectiva individual e o $\mathrm{Me}$ a perspectiva social e embora ambos possam se constituir em dois acessos diferentes à realidade, somente na medida em que o tomamos mutua e reciprocamente é que eles constituem o próprio Self. Mead trata de maneira sistemática este processo de profunda imbricação entre I e Me no parágrafo 22 de suas lições intituladas, mais tarde, de Mind, Self \& Society (MEAD, 1992, p. 173-178).

Georg Herbert Mead, a partir de sua teoria da dupla constituição do Self, afirma que toda socialização é interação, não havendo primazia da sociedade sobre o indivíduo e nem do indivíduo sobre a sociedade. O processo de subjetivação, desse modo, não é individual, porque acontece socialmente, na presença do outro. A partir desta interação com o outro e com o meio, cada si mesmo (Self) cria suas experiências, as quais permitem compreensões de mundo distintas entre os indivíduos. A experi- 
ência, nesse sentido, aponta para uma forma de ver o mundo e as coisas. O si mesmo, como identidade individual, nesse âmbito, não é dado a priori, mas é um processo de construção conflitiva entre a dimensão interna e a dimensão externa, que ocorre mediada linguisticamente pelo símbolo na presença do outro e do meio. Neste contexto, a tese de fundo de Mead é que é a linguagem humana em seu nível simbólico que proporciona a interação, pois através da linguagem os indivíduos se influenciam mutuamente e são impelidos à ação. Portanto, por meio da ação simbólica, resultado da interação social, os sujeitos constroem os seus mais diferentes acessos ao mundo.

Nesta altura da argumentação torna-se importante esclarecer melhor a noção de ação simbólica. Mead a toma como contraponto da ação gestual, a qual ele concebe como um nível mais elementar, primário, da linguagem humana. $\mathrm{O}$ mecanismo do gesto restringe-se a provocar estímulos, mas não permite a internalização de seu significado e nem do significado das reações provocadas nos outros indivíduos envolvidos. A ação simbólica, por sua vez, indo além da perspectiva reflexa e mecanizada da ação gestual, contém o elemento reflexivo que permite a internalização do sentido da ação, provendo um tipo de reação não só instintiva, mas também inteligente.

O símbolo significante nada mais é então do que a capacidade de internalização dos gestos vocais e sua posterior internalização com novos significados. Deste modo, a ação simbólica denota a capacidade reflexiva da linguagem humana, tornando possível que o processo de socialização mediado simbolicamente, seja um processo criativo e gerador de novos significados. Hans Joas, numa obra introdutória ao pensamento de Georg Herbert Mead, intitulada Praktische Intersubjetivität (Intersubjetividade prática) destaca a dimensão reflexiva da ação simbólica do seguinte modo: "Enquanto agimos, travamos relação não só com os objetos de nossas ações, senão também com os efeitos imediatos de nossas ações sobre nós mesmos. O falante ouve suas próprias exteriorizações linguísticas" (JOAS, 2000, p 109). É este processo de internalização reflexiva inerente à ação simbólica que é condição de ações autônomas e que também está na origem do próprio conteúdo ético da ação humana.

Se for compreendido que uma concepção pós-metafísica de educação diz respeito a um processo interativo entre sujeitos que se constituem enquanto identidades autônomas e livres, o Interacionismo simbólico de Georg Herbert Mead pode oferecer elementos conceituais para justificar essa concepção. O Interacionismo simbólico, com o conceito de ação humana enquanto interação mediada simbolicamente possibilita a compreensão da educação como uma ação mediada simbolicamente. Centrado no elemento simbólico, um processo dessa natureza permitire compatibilizar a dupla dimensão interna e externa do Self, tornando-se um processo livre e autônomo de formação de indivíduos com identidades igualmente livres e autônomas. Se isto é assim, então mostra coerência com formas democráticas de vida que caracterizam as sociedades contemporâneas, plurais e complexas.

Neste contexto, as formas democráticas de vida vêm sustentadas, filosoficamente, pela própria noção de intersubjetividade. Hans Jonas, na referida obra citada acima, define o sentido político inerente à intersubjetividade da seguinte forma: "No âmbito político, o conceito de intersubjetividade sinaliza para uma ordem social na 
qual a atomização dos indivíduos é superada, mas não pela sobreposição do coletivo, senão por meio de participantes que são capazes de argumentar a favor da determinação de seu futuro comum" (JOAS, 2000, p. 19). Ou seja, se nas sociedades contemporâneas, a atomização humana é um fato de primeira grandeza, ela precisa ser superada por um tipo de intersubjetividade que não simplesmente sobreponha o coletivo ao individual, pois Mead, como defensor da forma democrática de sociedade, tem claro que tal sobreposição conduz às formas totalitárias de sociedade. Por isso, desde o início, a intersubjetividade precisa incluir as liberdades individuais, baseadas na capacidade autônoma dos sujeitos que interagem simbolicamente.

Parece importante, todavia, destacar que ao se tornar um processo livre e autônomo de formação de indivíduos com identidades igualmente livres e autônomas, a educação não pode dispensar o elemento ético, que possibilita compatibilizar a dupla dimensão interna e externa do Self, não permitindo a sobreposição dualista e autoritária de um aspecto sobre o outro, o que estaria na contramão do que preconizou o próprio Interacionismo simbólico de Georg Herbert Mead. O desafio consiste em caracterizar esta ética, considerando que o si mesmo (Self) não se apresenta completamente transparente para si próprio, pois o ser humano apresenta dimensões constitutivas, a saber, “o inconsciente, a linguagem, a história e a mentalidade falibilista contemporânea” (CENCI, 2014, p. 13), sobre as quais não tem controle.

De qualquer forma, a dimensão ética brota da própria capacidade reflexiva inerente à ação simbólica. Mead defende a tese de que a ação humana por princípio não possui valor ético, porém, sem ação não há realização de valores. Isso está coerente com sua compreensão social da ética, segundo a qual ações éticas brotam da dupla estrutura constitutiva do Self, isto é, estão entrelaçadas com o I individual e o Me social. É esta própria duplicação simbólica do Self entre I e Me que possibilita ao processo educacional não ser apenas um caminho de mão única, liderado apenas pelo I ou pelo $\mathrm{Me}$, mas sim de mão dupla, onde I e Me não sejam instâncias isoladas e autossuficientes, mas sim dependestes do reconhecimento recíproco. Ora, é este reconhecimento recíproco que exige a inclusão ética do outro em minha própria ação.

\section{Considerações finais}

Resume-se, de maneira mais pontual, alguns possíveis alcances do Interacionismo simbólico ao campo educacional, sinalizando para os seguintes desdobramentos:

1) A postura filosófica do Interacionismo simbólico,alicerçado no conceito de ação mediada simbolicamente, conduz a perguntar o que significa educar no contexto da configuração social complexa, plural, pós-metafísica, a qual já não mais comporta - embora ainda esteja nela presente - a ideia de educação como extrair de dentro da criança, através da autoridade do adulto, uma essência pronta dada de antemão pelo grupo;

2) Se for compreendido que uma concepção pós-metafísica de educação diz respeito a um processo interativo entre indivíduos que se constituem enquanto 
identidades autônomas e livres, o Interacionismo simbólico de Georg Herbert Mead pode oferecer elementos conceituais para fundamentar essa concepção. A partir da compreensão do surgimento da mente e do Self numa perspectiva social e do conceito de ação humana enquanto interação mediada simbolicamente, o Interacionismo simbólico apresenta-se enquanto possibilidade de compreender a educação como processo interativo. Centrado no elemento simbólico, um processo dessa natureza permitiria compatibilizar a dupla dimensão interna e externa do Self, tornando-se um processo livre e autônomo de formação de indivíduos com identidades igualmente livres e autônomas. Isso se mostra então coerente com as formas democráticas de vida que caracterizam as sociedades plurais e complexas;

3) O Interacionismo simbólico torna-se importante a uma concepção pósmetafísica de educação porque considera a necessidade da presença do outro na construção da identidade individual, presença esta que se dá pela capacidade mediadora e reflexiva da ação simbólica. Tal capacidade reflexiva cria condições para uma formação qualificada do julgar moral e para o exercício democrático da cidadania, que são centrais à evolução da pessoa humana e da sociedade;

4) O desafio que pode se apresentar a partir de uma concepção pós-metafísica de educação fundamentada no Interacionismo simbólico de Georg Herbert está em construir uma base ético-política para a educação, sobretudo, a partir da descoberta de que há elementos constitutivos do ser humano (e portanto, de seu Self) que não são completamente transparentes para o indivíduo (o inconsciente, a linguagem, a história e a mentalidade falibilista contemporânea) e sobre as quais ele ainda não tem controle;

5) Por fim, a necessidade de repensar o papel da escola enquanto instância de construção da identidade dos indivíduos não em termos de um lugar-tempo que busca moldar indivíduos a partir de uma essência identitária em termos metafísicos ou baseada nos princípios da economia global de mercado e de consumo. Antes, cabe pensá-la como instância de tempo livre que permita ao indivíduo elaborar o processo de construção de seu Self na presença do outro, em um processo articulado aos princípios democráticos de autonomia, liberdade e solidariedade.

\section{Referências}

BAUMAN, Z. Modernidade Líquida. Rio de Janeiro: Jorge Zahar Editora, 2001.

CASAGRANDE, C.A. G.H. Mead \& a Educação. Coleção Pensadores \& Educação. Belo Horizonte: Autêntica, 2014.

CENCI, A.V. Emoções, ética e educação: elementos introdutórios à problemática da educabilidade das emoções, 2015. (Texto não publicado).

DALBOSCO, C. Pragmatismo, teoria crítica e educação: ação pedagógica como mediação de significados. Campinas, SP: Autores Associados, 2010.

DALBOSCO, C. Educação e formas de conhecimento: do inatismo antigo (Platão) e da educação natural moderna (Rousseau). Educação, v. 35, n. 2, Porto Alegre, maio/ago. 2012, p. 268-276. Disponível em:<http://revistaseletronicas.pucrs.br/ojs/index.php/faced/article/ view/11640/8032>. Acesso em: 09 out. 2016. 
DALBOSCO, C. Formação humana em sociedades complexas: espiritualidade e formas urbanas de vida. In: MÜHL, E.; DALBOSCO, C.; CENCI, A. (Orgs). Questões atuais da Educação. Sociedade Complexa, pensamento pós-metafísico, democracia e formação humana. Ijuí: Editora Unijuí, 2016a, p.183-207.

DALBOSCO, C. Educação em sociedades tradicionais e sociedades complexas: o problema da crise da autoridade. In: MÜHL, E.; DALBOSCO, C.; CENCI, A. (Orgs). Questôes atuais da Educação. Sociedade Complexa, pensamento pós-metafísico, democracia e formação humana. Ijuí: Editora Unijuí, 2016b, p.51-78.

GIDDENS, A. Modernidade e Identidade. Tradução de Plínio Dentzien. Rio de Janeiro: Jorge Zahar Ed., 2002.

GOERGEN, P. Formação Humana e sociedades plurais. Revista Espaço Pedagógico, v.21, n.1, Passo Fundo, jan./jun. 2014, p.23-40.

JOAS, H. Interacionismo simbólico. In: GIDDENS, A. \& TURNER, J. (ORGs.). Teoria social hoje. São Paulo: Editora UNESP, (p. 127-174),1999.

JOAS, H. Praktische Intersubjektivität. Die Entwicklung des Werkes von G. H. Mead. Frankfurt am Mai: Suhrkamp, 2000.

KANT, E. Sobre a Pedagogia. Coimbra: Almedina, 2012.

LOCKE, J. Alguns Pensamentos Sobre a Educação. Coimbra: Almedina: 2012.

MEAD. G. H. Mind, Self \& Society. From the standpoint of a social behaviorist. Chicago: University Press, 1992.

PLATÃO. Diálogos: Critão - Menão - Hípias Maior e outros. Tradução de Carlos Alberto Nunes. Belém: Editora Universitária, 2007.

ROUSSEAU, J. J. Emilio ou da educação. Rio de Janeiro: Bertrand Brasil, 1992.

SENNETT, R. O declínio do homem público. As tiranias da intimidade. São Paulo: Campanhia das Letras, 1988.

STANFORD. Encyclopedia of Philosophy. George Herbert Mead (Org.). 2012. Disponível em: <http://plato.stanford.edu/entries/mead/>. Acesso em: 05 abr. 2015.

\section{Notas}

${ }^{1}$ A primeira versão deste artigo foi apresentada ao NUPEFE (Núcleo de Pesquisas em Filosofia e Educação) do Programa de Pós-graduação em Educação da Universidade de Passo Fundo (UPF). Agradecimento especial aos professores, pesquisadores e participantes desse grupo pelas enriquecedoras contribuições.

${ }^{2}$ No contexto da tradição pedagógica ocidental, a origem clássica desta perspectiva metafísica é o Menão, de Platão (PLATÃO, 2007). Neste diálogo, Sócrates faz o escravo "extrair de dentro" conhecimentos matemáticos, sem nunca ter frequentado a escola ou ter conversado sobre o assunto. Para uma crítica a esta perspectiva ver Dalbosco (2012).

${ }^{3}$ Pensada no horizonte do pensamento pós-metafísico, a idéia de fundamentação não está mais vinculada à consciência como substância e, por isso, não se sustenta mais no conceito forte de fundamentação última. Como brota da ação mediada simbolicamente, a noção de fundamento é derivada de uma racionalidade fraca, passível de erros a serem corrigidos pelo próprio processo linguístico, ou seja, pelo agir comunicativo inerente à linguagem humana. Fica claro, com isso, que a noção de fundamento admitida pelo Interacionismo simbólico refere-se a uma racionalidade de tipo processual e falibilista, não mais, portanto, dogmática, no sentido de fundamentação última. 


\section{Cláudio Almir Dalbosco - Renata Maraschin}

${ }^{4}$ Esse panorama amplo e complexo está apresentado, de forma mais detalhada, por exemplo, em GOERGEN (2014) e DALBOSCO (2016a; 2016b).

${ }^{5}$ Do ponto de vista histórico-sistemático, o iluminismo pedagógico inicia, em sua versão inglesa, ainda no século XVII, com Pensamentos acerca da Educação, de John Locke (LOCKE, 2012). No contexto do iluminismo francês, o Emílio, de Jean-Jacques Rousseau (ROUSSEAU, 1992) assume papel de proa. Por fim, no contexto alemão, as aulas proferidas por Emmanuel Kant, na Universidade de Königsberg e publicadas com o título Sobre a Pedagogia (KANT, 2012) sintetiza, em certo sentido, este longo desenvolvimento iluminista de mais de um século.

* Professor doutor da Universidade de Passo Fundo, Passo Fundo, Rio Grande do Sul. Brasil.

** Doutoranda em Educação pela Universidade de Passo Fundo, Passo Fundo, Rio Grande do Sul. Brasil.

\section{Correspondência}

Cláudio Almir Dalbosco - Universidade de Passo Fundo, Faculdade de Educação. Campus I - Bairro São José. CEP: 99010-290. Passo Fundo, Rio Grande do Sul, Brasil.

E-mail: cadalbosco@upf.br -rechinpf@gmail.com

Recebido em 26 de setembro de 2016

Aprovado em 02 de dezembro de 2016 